\title{
Junctional communication of pancreatic $\beta$ cells contributes to the control of insulin secretion and glucose tolerance
}

\author{
Anne Charollais, ${ }^{1}$ Asllan Gjinovci, ${ }^{2}$ Joachim Huarte, ${ }^{1}$ Juliette Bauquis, ${ }^{1}$ Angel Nadal, ${ }^{3}$ \\ Franz Martín, ${ }^{3}$ Etelvina Andreu, ${ }^{3}$ Juan V. Sánchez-Andrés, ${ }^{3}$ Alessandra Calabrese,${ }^{1}$ \\ Domenico Bosco, ${ }^{1}$ Bernat Soria, ${ }^{3}$ Claes B. Wollheim, ${ }^{2}$ Pedro L. Herrera, ${ }^{1}$ and Paolo Meda ${ }^{1}$
}

${ }^{1}$ Department of Morphology, and

${ }^{2}$ Department of Medicine, University of Geneva, Medical School, Geneva, Switzerland

${ }^{3}$ Institute of Bioengineering, University Miguel Hernandez, San Juan de Alicante, Spain

Address correspondence to: Paolo Meda, Department of Morphology, University of Geneva,

Centre Medical Universitaire, 1 rue Michel Servet, 1211 Geneva 4, Switzerland. Phone: 4122-7025210;

Fax: 4122-7025260; E-mail: Paolo.Meda@medecine.unige.ch.

Received for publication January 17, 2000, and accepted in revised form June 7, 2000.

\begin{abstract}
Proper insulin secretion requires the coordinated functioning of the numerous $\beta$ cells that form pancreatic islets. This coordination depends on a network of communication mechanisms whereby $\beta$ cells interact with extracellular signals and adjacent cells via connexin channels. To assess whether connexin-dependent communication plays a role in vivo, we have developed transgenic mice in which connexin 32 (Cx32), one of the vertebrate connexins found in the pancreas, is expressed in $\beta$ cells. We show that the altered $\beta$-cell coupling that results from this expression causes reduced insulin secretion in response to physiologically relevant concentrations of glucose and abnormal tolerance to the sugar. These alterations were observed in spite of normal numbers of islets, increased insulin content, and preserved secretory response to glucose by individual $\beta$ cells. Moreover, glucose-stimulated islets showed improved electrical synchronization of these cells and increased cytosolic levels of $\mathrm{Ca}^{2+}$. The results show that connexins contribute to the control of $\beta$ cells in vivo and that their excess is detrimental for insulin secretion.
\end{abstract}

J. Clin. Invest. 106:235-243 (2000).

\section{Introduction}

Communication through connexin channels is an almost ubiquitous mechanism for intercellular signaling within tissues (1). However, the physiological functions of this communication and the mechanisms that underlie these functions are still undetermined in most tissues, including secretory epithelia $(1,2)$.

The pancreatic $\beta$ cells that produce insulin are also interconnected by connexin channels (2). Previous experiments have suggested that, at least in vitro, these channels contribute to regulate insulin biosynthesis and release. Thus, single $\beta$ cells, which are not coupled by connexin channels, show a poor expression of the insulin gene, release low amounts of the hormone, and barely increase these functions after stimulation (2-4). Restoration of $\beta$-cell contacts is paralleled by a rapid improvement of both insulin biosynthesis and release (2-4). The findings that drugs that block connexin channels prevent this improvement (4) and that sustained stimulation of insulin release results in increased $\beta$-cell coupling whereas inhibition of insulin secretion decreases or abolishes it $(2,5)$, indicate that junctional coupling may be a key event (4). Further support for this view has come from the finding that a number of tumoral and transformed cell lines that show abnormal secretory characteristics do not express connexins and are uncoupled (6). Transfection of a connexin gene corrected in parallel the coupling and some of the secretory defects, at least in clones that featured moderate levels of connexin expression (6).

To our knowledge, however, no study to date has shown whether connexin-dependent coupling is relevant for the functioning of native $\beta$ cells in vivo and, if so, how it is integrated with the other signaling mechanisms that contribute to control $\beta$-cell function. Specifically, it remains to be shown whether an alteration of connexins is sufficient to alter insulin secretion and to affect blood glucose, two parameters that are regulated by multiple mechanisms and whose proper control is a landmark of adequate $\beta$-cell function (7-10).

Here, we have used a transgenic approach to change the pattern of connexins expressed by native $\beta$ cells. Because cells of pancreatic islets express multiple connexins, whose precise distribution and roles remain to be ascertained (11), and given that the deletion of at least one of these connexins is lethal immediately after birth (12), we have chosen to selectively force $\beta$ cells to express another connexin, referred to as Cx32 (13). This protein, which is not expressed in native pancreatic islets (14), shares a number of essential structural and functional features with islet cell connexins (15-17). We show that mice featuring excessive $\beta$-cell coupling, as a result of $\mathrm{Cx} 32$ expression, have a much reduced insulin secretion and an abnormal tolerance to glucose, 
in spite of a preserved ionic and secretory responsiveness of individual $\beta$ cells to the sugar. The results provide novel in vivo evidence that proper levels of junctional communication are essential for normal control of $\beta$-cell function.

\section{Methods}

Transgenic mice. A construct was designed (Figure 1a) by ligating in series a 460-bp sequence of the rat insulin II promoter (RIP; ref. 18), a cDNA that comprised the entire coding region of rat $\mathrm{Cx} 32$ (13) and part of the human growth hormone, as a source of introns and polyadenylation signals (19). An Xba1/Xho1 fragment containing the $\mathrm{Cx} 32$ transgene was microinjected into zygotic pronuclei, and surviving embryos were transferred into pseudopregnant female mice (19). Transgenic founders were identified by dot blot screening of tail DNA, using probe 1 , along the hGH sequence, and by Southern blot of EcoR1-digested DNA, using probe 2 along the sequence of rat Cx32 (Figure 1a). Two positive founder mice were successfully breed with C57BL/6 controls to generate two independent lines of transgenic animals, referred to as D6 and B9, respectively. Heterozygous transgenic mice were identified in the progeny by PCR amplification of tail DNA, using primers hybridizing to the hGH sequence (Figure 1a). Homozygous mice were obtained by crossing heterozygous D6 animals and were identified by dot blot, using probe 1 . Candidates were certified for homozygosity by testing the progeny obtained in crossings with C57BL/ 6 controls partners. All animals were kept under standard housing conditions, and experiments were conducted according to the regulations of our institutional and state committees on animal experiments.

Immunolabeling. Pancreas fragments were frozen in liquid nitrogen and embedded in Tissue-Tek (Sakura Finetechnical Co., Tokyo, Japan). Cryosections were exposed 3 minutes to $-20^{\circ} \mathrm{C}$ acetone, rinsed in PBS containing $0.5 \% \mathrm{BSA}$, and incubated 2 hours at room temperature with a rabbit polyclonal serum against Cx32, diluted 1:200 (14). After rinsing, sections were exposed for 1 hour at room temperature to sheep antibodies against rabbit Ig's, diluted 1:400, and photographed. Controls included omitting the primary antibody and incubating sections of tissues known to express no (mouse heart and control pancreatic islets) or much (mouse liver and exocrine pancreas) Cx32, according to the protocol just described. Pancreas sections and single cells were also immunostained for insulin, GLUT2, and glucokinase (20) and evaluated by standard morphometric methods.

Junctional coupling. Islets of Langerhans isolated by collagenase digestion were attached to poly-L-lysine-coated dishes (4), and individual cells were impaled using a glass microelectrode filled with 4\% Lucifer Yellow CH (Sigma Chemical Company, St. Louis, Missouri, USA). Iontophoretic injection of the tracer was performed for 5 minutes using $0.1 \mathrm{nA}$ negative square pulses of 900millisecond duration and $0.5-\mathrm{Hz}$ frequency (4). After the injected field was photographed, the islets were fixed in $4 \%$ paraformaldehyde and embedded in Epon. Serial sections $(1 \mu \mathrm{m})$ were photographed under ultraviolet illumination. The extent of coupling was determined by measuring the area stained by Lucifer Yellow immediately after each injection and by scoring the number of cells that had retained the tracer in the sections (4).

Insulin secretion and content. Mice were anesthetized with $100 \mathrm{mg} / \mathrm{kg}$ body weight sodium pentothal intraperitoneally and prepared for pancreas perfusion as described elsewhere (21). The pancreas was perfused at $37^{\circ} \mathrm{C}$ with $1 \mathrm{~mL} / \mathrm{min}$ modified Krebs-Ringer-HEPES buffer supplemented with the indicated concentrations of glucose. After the first 30 minutes, during which no sample was taken, the pancreatic effluent was collected in 1-minute aliquots from a catheter placed in the portal vein. Insulin content of each aliquot was measured by RIA (4). Differences in insulin secretion between animals and groups were assessed by a Student's $t$ test that compared the areas under the secretion curve, for each consecutive 20-minute period. Batches of 10 isolated islets were similarly tested in static incubations (4). Fragments of intact pancreas and batches of isolated islets were extracted in acidethanol for determination of insulin content (4).

Glucose tolerance. Sex- and age-matched mice were fasted overnight for 15 hours and briefly anesthetized with 5\% Ethrane (Abbott Laboratories, Cham, Switzerland) for sampling blood in the ophthalmic plexus. The animals were then injected i.p with $0.11 \mathrm{mg} / \mathrm{g}$ body weight of glucose, and blood samples were taken at the indicated intervals. Blood glucose was measured in each sample using an Accutrend reader and reagent sticks (Boehringer Mannheim, Germany). Insulin levels were measured in plasma using a rat insulin ELISA (Mercodia AB, Uppsala, Sweden).

Secretion of single cells. Cells were dispersed by exposing isolated islets to a medium devoid of $\mathrm{Ca}^{2+}$ and $\mathrm{Mg}^{2+}$ and supplemented with $0.1 \%$ trypsin (1:250; Difco Laboratories, Detroit, Michigan, USA). After attachment to poly-L-lysine-coated chambers, cells were studied for insulin secretion in a reverse hemolytic plaque assay, as described previously $(4,20)$. Secretion was evaluated by scoring the number and size of hemolytic plaques that developed around single cells after a 30-minute incubation in the presence of the indicated glucose concentration and by calculating total plaque development (20).

Connexin channels of single cells. Dispersed islet cells were exposed for 30 minutes at $37^{\circ} \mathrm{C}$ to $0.85 \mu \mathrm{M}$ biscarboxylethylcarboxyfluorescein-acetoxy-methylester (BCECF-acetoxy-methylester; Molecular Probes Inc., Eugene, Oregon, USA) (22), washed in Dulbecco's minimal essential culture medium and examined under an Axiophot microscope (Carl Zeiss, Jena, Germany). At least 100 cells were scored in two experiments for cytoplasmic fluorescence, once immediately after loading of BCECF and once after a 4-hour culture at $37^{\circ} \mathrm{C}$.

Electrophysiological recordings. Microdissected islets were attached in a $50-\mu \mathrm{L}$ chamber and perfused at 
$\mathbf{a}$

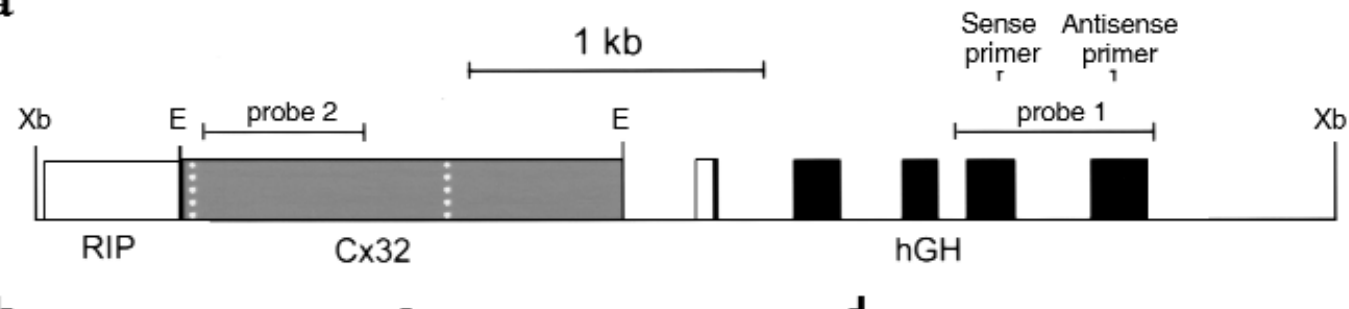

b

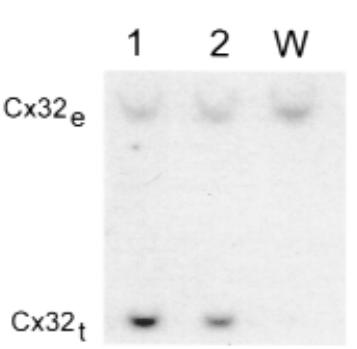

c

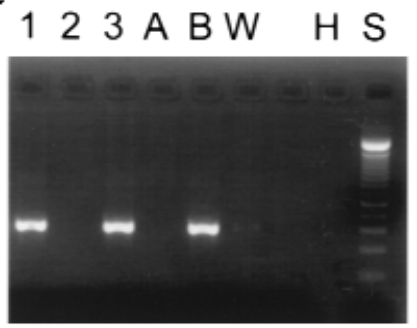

d

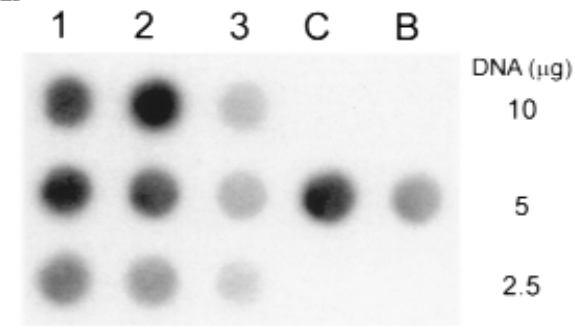

Figure 1

Strategy for expressing Cx32 in pancreatic $\beta$ cells. (a) A transgene that contained part of the RIP, the second exon of Cx32 cDNA (Cx32; coding region limited by dots), and the coding region of human growth hormone gene (hGH) was microinjected into zygotic pronuclei, and surviving embryos were transferred into pseudopregnant foster mothers. (b) Transgenic mice were screened by Southern blot using probe 2. Compared with wild-type controls $(\mathrm{W})$, which featured only the 7.6-kb endogenous gene $\left(\mathrm{C} \times 32_{\mathrm{e}}\right)$, two positive founders were identified that also expressed the $1.5-\mathrm{kb}$ transgene $\left(\mathrm{C} \times 32_{\mathrm{t}}\right)$. These mice were backcrossed with $\mathrm{C} 56 \mathrm{BL} / 6$ controls to generate the two independent lines $\mathrm{B} 9$ (lane 1) and D6 (lane 2). (c) The progeny were screened by PCR using primers along the hGH sequence. Heterozygous mice carrying the transgene (lanes 1, 3, and B) were distinguished from control littermates (lanes 2 and A) and wild-type controls (W) by the amplification of a 390-bp product (lane H, water; lane S, standards). (d) Heterozygous mice of the D6 line were further crossed to obtain a homozygous progeny. Mice carrying two alleles of the transgene (lanes 1 and 2) were distinguished from heterozygous littermates (lane 3 ) by hybridizing DNA with probe 1. Dot intensity was compared with that observed with DNA of mice from previous litters, whose homozygosity (lane C) or heterozygosity (lane B) had been biologically controlled by crossing with C57BL/ 6 controls.

$37^{\circ} \mathrm{C}$ with $0.8 \mathrm{~mL} /$ min modified Krebs medium (23), supplemented with the indicated glucose concentration. Individual cells were impaled using borosilicate glass microelectrodes of 80-120 M $\Omega$. Cell membrane potentials were recorded using an Axoclamp 2B amplifier, acquired using Axoscope 1.0 (Axon Instruments Inc., Foster City, California, USA), and analyzed with Origin 4.1 (Microcal Software Inc., Northampton, Massachusetts, USA) (23). Electrical activity was evaluated by plotting the ratio of active phase to total peri$\mathrm{od}$, as a function of glucose concentration. To evaluate electrical synchronization, two $\beta$ cells were simultaneously recorded with electrodes distant by $80 \pm 15 \mu \mathrm{m}$ (23). Synchronization was evaluated by measuring the interval between corresponding spikes on the recordings of the two $\beta$ cells.

Monitoring of $\mathrm{Ca}^{2+}$ changes. Collagenase-isolated islets loaded with $5 \mu \mathrm{M}$ Indo-1 AM (Molecular Probes Inc.) at room temperature, were monitored for emitted fluorescence under a 350-nanometer excitation provided by a 75-W mercury lamp (24). This fluorescence was split into two beams with a dichroic mirror, filtered at 410 and 480 nanometers, and detected by two photomultipliers (Thorn EMI Electron Tubes Ltd., Ruislip, United Kingdom). Increase in $\left[\mathrm{Ca}^{2+}\right]_{i}$ elicited a rise of the 410nanometer fluorescence and a decrease of that at 480 nanometers. Records were expressed as the ratio of fluorescence at 410 and 480 nanometers (24). The duration of $\mathrm{Ca}^{2+}$ increase was evaluated in 6- to 10 -minute record- ings, by measuring the time during which $\left[\mathrm{Ca}^{2+}\right]_{i}$ levels remained above half-peak value. $\left[\mathrm{Ca}^{2+}\right]_{\mathrm{i}}$ was also evaluated in individual cells dispersed from isolated islets and loaded with $5 \mu \mathrm{M}$ Fluo-3/AM (Molecular Probes, Leiden, The Netherlands), using a confocal microscope (Zeiss LSM 510; Carl Zeiss) that allowed fluorescence measurements every 2 seconds.

\section{Results}

Two lines of transgenic mice were generated that, in contrast to control littermates, expressed the DNA coding for $\mathrm{Cx} 32$ under control of RIP (Figure 1b). In both lines, the transgene was found to be expressed throughout the generations of heterozygous animals that were backcrossed with C57BL/ 6 mice for more than 3 years (Figure 1c). Heterozygous mice of the D6 line, which were used in most of the experiments, were further crossed to obtain a homozygous progeny (Figure 1d). The presence of two alleles of the transgene in this progeny was certified by crossing the homozygous candidates with wild-type C57BL/6 partners. All resulting pups were heterozygous for the RIPCx32 transgene (data not shown).

Frozen sections of pancreas were immunostained with antibodies to Cx32, to confirm that RIP had actually directed the expression of this connexin in pancreatic $\beta$-cells. In wild-type controls, the antibodies revealed a punctate decoration of the acinar cells of exocrine pancreas, but did not stain the hormone-pro- 


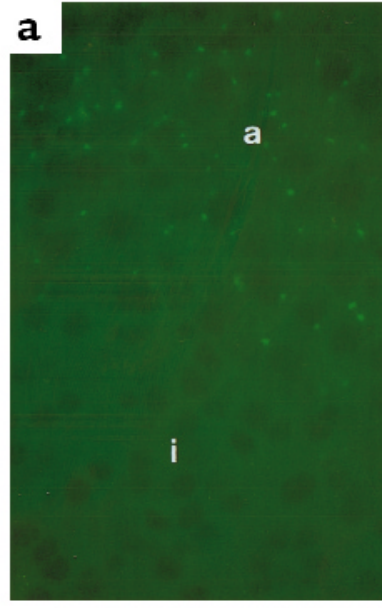

b

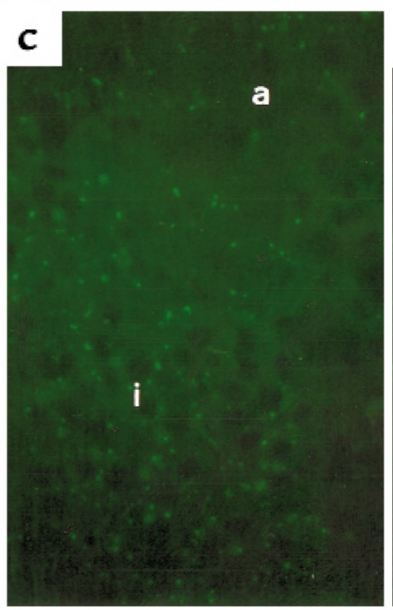

\section{Figure 2}

Transgenic mice express Cx32 in pancreatic islets. (a) Antibodies against $\mathrm{C} \times 32$ immunostained this protein in acinar cells of exocrine pancreas (a), but failed to reveal it in endocrine cells of pancreatic islets (i). (c and $\mathbf{d}$ ) In contrast, the same antibodies resulted in a punctate immunostaining of islet cells in both heterozygous (c) and homozygous (d) mice. Scale bar, $30 \mu \mathrm{m}$. (b) Islet immunostaining was about twice as high in homozygous (solid column) than in heterozygous (open column) animals. Data are mean \pm SEM of the indicated number of islets.

ducing cells of endocrine islets (Figure 2a). The same antibodies resulted in an obvious labeling of $\beta$ cells, which comprise the center of islets, in heterozygous (Figure 2c) and homozygous (Figure 2d) transgenic mice. Quantitative evaluation of the number of immunofluorescent spots showed that islet immunostaining was about twice as high $(P<0.001)$ in homozygous as in heterozygous animals (Figure $2 \mathrm{~b}$ ).

To ensure that $\mathrm{C} \times 32$ had formed functional channels in transgenic mice, we investigated the intercellular diffusion of Lucifer Yellow CH. Microinjection of this membrane-impermeant tracer into individual $\beta$ cells resulted in a spatial diffusion that was limited in islets isolated from control mice (Figure 3a) and much larger in islets isolated from transgenic animals of both the D6 (Figure $3 \mathrm{~b}$ ) and B9 line, irrespective of their heterozygous or homozygous genotype. Sections of the injected areas con- firmed that the difference was due to a larger $(P<0.001)$ number of cells exchanging the tracer in transgenic than in control animals (Figure 3, c-f).

To assess whether the increased coupling of transgenic $\beta$ cells affected their secretion, we perfused in situ the intact pancreas with glucose levels of 1.4-16 $\mathrm{mM}$ and measured insulin output during six consecutive 20-minute periods. Under these conditions, control mice showed a progressive increase in insulin secretion that was elevated $(P<0.02)$ over basal value already at $6.0 \mathrm{mM}$ glucose and increased thereafter (Figure 4, a and b). In the presence of $16 \mathrm{mM}$ glucose, the insulin output of control pancreas was about ninefold $(P<0.001)$ that under basal conditions (Figure $4 \mathrm{~b})$. This response was markedly decreased in heterozygous mice of the D6 line, whose insulin release represented $33 \%(P<0.005)$ and $43 \%(P<0.03)$ of controls in the presence of 8.0 and $16 \mathrm{mM}$ glucose, respectively (Figure 4, a and b). A comparable decrease was observed in the heterozygous mice of the B9 line (data not shown) and was more marked in the homozygous D6 animals, whose secretion in the presence of $16 \mathrm{mM}$ glucose represented $23 \%(P<0.007)$ and $52 \%(P<0.09)$ of control and heterozygous values, respectively (Figure $4 \mathrm{~b}$ ). Homozygous mice also featured an elevated $(P<0.01)$ basal insulin output (Figure $4 \mathrm{~b})$.

To assess whether these alterations in insulin secretion were sufficient to influence the levels of circulating glucose, we tested the tolerance of sex- and agematched littermates to an acute load of glucose, which was chosen to raise $(P<0.001)$ glycemia in 5 minutes to postprandial levels. The glycemia of controls returned to basal values within 1 hour (Figure 5a). At this time point, transgenic mice featured blood glucose levels significantly higher $(P<0.001)$ than their initial basal values, which were lower $(P<0.003)$ than those of controls (Figure 5a). The ratio of glucose-stimulated/basal glycemia, which averaged 1 in control mice from 60 minutes onward (Figure 5b), remained significantly elevated in both heterozygous and homozygous mice, throughout the 2-hour duration of the test (Figure 5b). Similar observations were made by testing glycemia 3 hours after starved animals were allowed free access to laboratory chow, and in heterozygous mice of the B9 line (data not shown).

To evaluate whether the changes in blood glucose correlated with changes in plasma insulin, we first measured the hormone at the end of the fasting period. We found that insulin levels were $0.19 \pm 0.03,0.31$ $\pm 0.04(P<0.05)$, and $0.38 \pm 0.05 \mathrm{ng} / \mathrm{mL}(P<0.008)$ in control, heterozygous and homozygous littermates $(n=12$ each), respectively. Fifteen minutes after the glucose injection, these values increased $(P>0.02)$ in control $(0.41 \pm 0.07)$ but not transgenic $(0.36 \pm 0.11$ and $0.28 \pm 0.04)$ animals. Thus, the glucose-induced increase in circulating insulin was $2.4 \pm 0.4,1.1 \pm 0.2$ $(P<0.02)$, and $1.2 \pm 0.2$ fold $(P<0.02)$ in control, heterozygous and homozygous littermates, respectively.

To explore whether the secretory defect of transgenic 
mice was due to a loss in islets, we analyzed morphometrically four pancreas per genotype, after insulin immunostaining. We found that all animals had similar numbers of islets per $100 \mathrm{~mm}^{2}$ of pancreas (median, 4-6) and that the area of individual islet profiles (> 200 islets were scored per group) had a median value of 1.2 , $2.5(P<0.001)$, and $4.0 \mu \mathrm{m}^{2}(P<0.001)$ in control, heterozygous and homozygous transgenics, respectively. Total insulin content of pancreas was $0.06 \pm 0.01,0.12$ $\pm 0.1(P<0.003)$, and $0.11 \pm 0.2 \mathrm{ng} / \mathrm{mg}(P<0.003)$ in 5 control, 11 heterozygous, and 6 homozygous mice, respectively. To assess whether the secretory defect of transgenic mice resulted from a loss in key glucose-sensing proteins, we immunolabeled pancreas sections for GLUT2 and glucokinase. We found that these two proteins were detectable in most insulin-containing cells of the three animal groups we compared (data not shown).

To explore whether the RIP-driven expression of $\mathrm{C} \times 32$ resulted in a nonspecific loss of glucose responsiveness, we tested the secretion of single $\beta$ cells in a reverse hemolytic plaque assay. In three experiments, we found that cells dispersed from heterozygous and homozygous transgenics had a lower basal secretion than control cells (total plaque development in the presence of $1.4 \mathrm{mM}$ glucose was $103.0 \pm 49.1$, $13.6 \pm 5.5$, and $9.6 \pm 2.9 \mu \mathrm{m}^{2}$, respectively. Both transgenic and control cells increased $(P<0.001)$ their insulin secretion after exposure to either 8.4 or $16.7 \mathrm{mM}$ glucose. The ratio of the total plaque development values evaluated in the presence of 16.7 and $1.4 \mathrm{mM}$ glucose showed that this increase was not lower in the two groups of transgenics than in controls $(51.2 \pm 16.3,41.3$ \pm 14.1 , and $20.7 \pm 14.0$ fold, respectively).

To test whether the preserved glucose sensitivity of single cells was altered by cell contact, we evaluated the secretion of isolated islets. We found that after $30 \mathrm{~min}-$ utes of exposure to $1.4 \mathrm{mM}$ glucose, islets released $0.6 \pm$ $0.4,3.0 \pm 0.6(P>0.001)$, and $3.5 \pm 0.6 \%(P>0.001)$ of their insulin content in control, heterozygous, and homozygous mice ( $n=20$ in each group), respectively. In contrast to control islets, whose secretion increased $(P<$ $0.001)$ in the presence of both $8.4 \mathrm{mM}(1.3 \pm 0.1 \%, n=20)$ and $16.7 \mathrm{mM}$ glucose $(2.8 \pm 0.3 \%, n=20)$, islets of transgenic mice did not raise their insulin output in the presence of either glucose concentration ( $8.4 \mathrm{mM}: 2.8 \pm 0.7$ and $2.6 \pm 0.4 \% ; 16.7 \mathrm{mM}: 2.6 \pm 0.4$ and $2.4 \pm 0.4 \%$ in 20 heterozygous and homozygous mice, respectively).

To assess whether a loss of the intercellular signaling due to current-carrying ions was involved in the poor secretion of transgenic animals, we recorded simultaneously the membrane potential of two $\beta$ cells within microdissected islets. We found that both control and transgenic $\beta$ cells were electrically stimulated by glucose above $10 \mathrm{mM}$, with a similar dose-dependence (data not shown). In the presence of $11 \mathrm{mM}$ glucose, both cell types featured typical depolarization bursts with spikes, separated by periods of repolarization (Figure 6a). Although the duration of bursts (active phase) and the time between them (silent phase) were longer
$(P<0.01)$ in transgenic than control islets (Figure 6a), the ratio of active phase/total period, which reflects the degree of electrical activity, was the same in the two groups $\left(\mathrm{EC}_{50}\right.$ of active phase was $1.08 \pm 0.01$ and $1.07 \pm$ $0.01 \log$ [glucose] in 10 transgenic and 20 control cells). However, although this electrical activity was slightly asynchronous in $\beta$ cells of controls, where spikes occurred with a delay of $890 \pm 215$ milliseconds, it was fully synchronous in transgenic animals (Figure 6a).

To assess whether a failure of free cytosolic calcium to increase during glucose stimulation could account for the poor secretion of transgenic animals, we evaluated fluorometrically the changes in this cation within intact
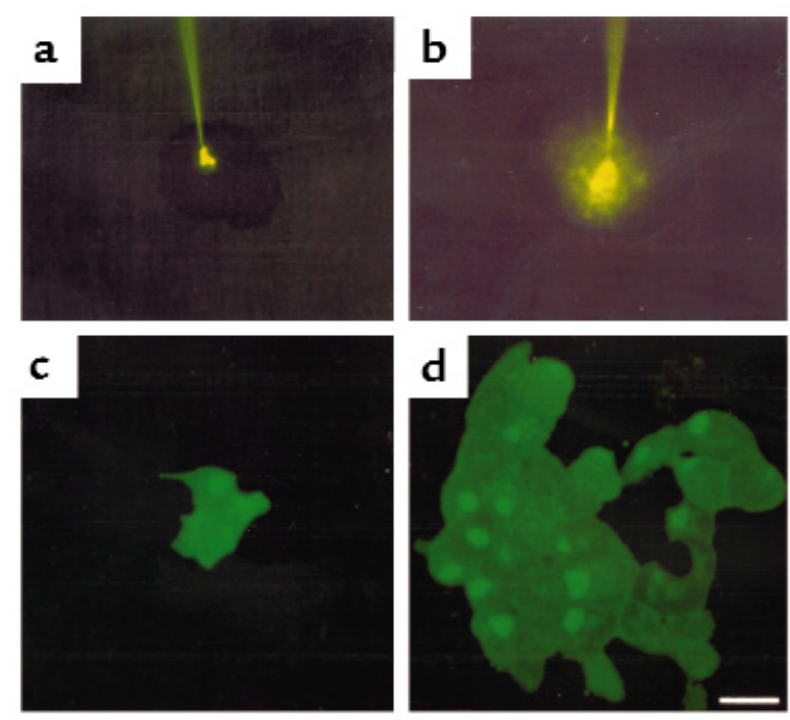

e

f
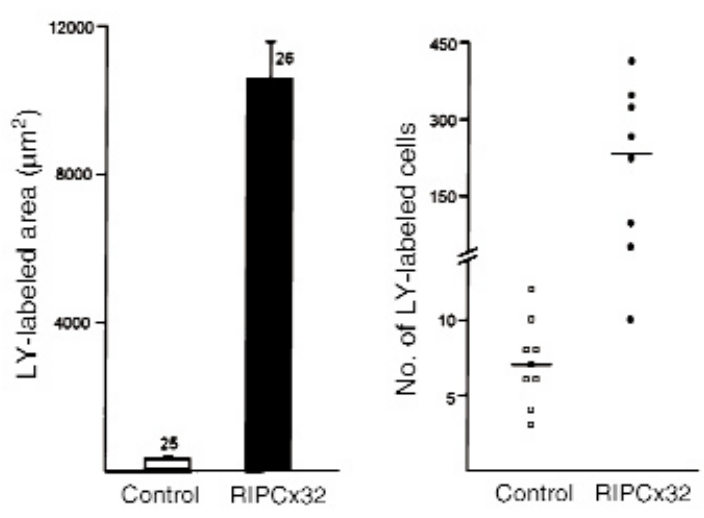

Figure 3

Cx32 increases coupling of pancreatic $\beta$ cells. (a and $\mathbf{b}$ ) Microinjection resulted in an intercellular transfer of Lucifer Yellow that was limited within islets isolated from control mice (a) and much larger within islets isolated from transgenic animals (b). (c and d) Sections of the injected areas showed that the number of $\beta$ cells that exchanged Lucifer Yellow was larger in transgenic (d) than control (c) islets. Scale bar: $120 \mu \mathrm{m}$ (a and b), $17 \mu \mathrm{m}$ (c and d). (e and f) Dye coupling was 30- to 40-fold larger in transgenic (solid column and circles) than control mice (open column and squares). Data in e are mean \pm SEM of the indicated number of islets. Symbols in $\mathbf{f}$ represent individual islets; bar = median. LY, Lucifer Yellow. 


\section{Figure 4}

Transgenic mice expressing Cx32 show altered insulin secretion. (a) Insulin secretion from in situ perfused pancreas was evaluated during six 20-minute periods that consecutively tested glucose concentrations from 1.4-16 mM glucose. Control mice (open squares) showed a progressive increase in insulin output as glucose concentration increased. In contrast, transgenic mice (solid circles; heterozygous and homozygous animals pooled) were essentially unaffected by glucose concentrations up to $8 \mathrm{mM}$ and poorly stimulated at higher concentrations of the sugar. Data are mean \pm SEM of the indicated number of animals. (b) The cumulative insulin output of control pancreas (open bars) perfused with 8 and $16 \mathrm{mM}$ glucose was 4.2 - and 9-fold higher than that measured in the presence of $1.4 \mathrm{mM}$ of the sugar, respectively. Heterozygous transgenic mice (gray bars) showed a reduced response to both $8 \mathrm{mM}(P<0.005)$ and $16 \mathrm{mM}(P<0.03)$ glucose, their average insulin output being only 1.9 - and 5.5 -fold higher than basal level in the presence of these two glucose concentrations, respectively. Compared with controls, homozygous transgenic mice (solid bars) also showed a reduced insulin output in the presence of both $8 \mathrm{mM}(P<0.02)$ and $16 \mathrm{mM}$ glucose $(P<0.007)$, their average insulin output being similar to basal level in the presence of the two glucose concentrations. Data are mean \pm SEM of the indicated number of animals. ${ }^{A} P<0.05$; difference between values evaluated for successive glucose concentrations. ${ }^{\mathrm{B}} P<0.02$; difference between values evaluated for successive glucose concentrations. $C P<0.001$; difference between values evaluated for successive glucose concentrations.

islets. We found that the fluorescence ratio reflecting $\left[\mathrm{Ca}^{2+}\right]_{\mathrm{i}}$ was lower $(P<0.05)$ in control than transgenic mice in the presence of $5 \mathrm{mM}$ glucose $(2.2 \pm 0.2, n=13$ and $2.8 \pm 0.3, n=11$, respectively) and increased with an oscillatory pattern in most islets perfused with $11 \mathrm{mM}$ glucose (Figure $6 \mathrm{~b}$ ). Although the duration of active and silent phases were longer $(P<0.001)$ in transgenic than control islets (Figure $6 \mathrm{~b}$ ), the fractional time during which $\left[\mathrm{Ca}^{2+}\right]_{\mathrm{i}}$ was increased was similar in the two types of animals (43 \pm 6 and $44 \pm 4 \%$, respectively). However, the amplitude of the $\left[\mathrm{Ca}^{2+}\right]_{\mathrm{i}}$ increase over basal value was higher $(P<0.01)$ in transgenic than control mice $(0.88 \pm$ 0.16 and $0.45 \pm 0.06$, respectively).

To assess whether these differences in $\mathrm{Ca}^{2+}$ handling occurred independently of cell coupling, possibly as a result of permanently patent connexin channels, we monitored basal and glucose-stimulated $\left[\mathrm{Ca}^{2+}\right]_{\mathrm{i}}$ in single cells. No significant difference in $\left[\mathrm{Ca}^{2+}\right]_{\mathrm{i}}$ was observed between control $(n=35)$ and transgenic $(n=$ 32) cells in the presence of $3 \mathrm{mM}$ glucose. Both cell populations also showed similar $\left[\mathrm{Ca}^{2+}\right]_{i}$ oscillations when glucose was raised to $22 \mathrm{mM}$ (data not shown). Furthermore, connexin channels of single cells were found not to be opened, as evaluated by the retention in the cytoplasm of BCECF, in all the control and transgenic cells that were investigated (data not shown).

\section{Discussion}

Connexin channels connect the secretory cells of all the multicellular glands that have thus far been investigated, including pancreatic islets $(2,11,14)$. Previous in
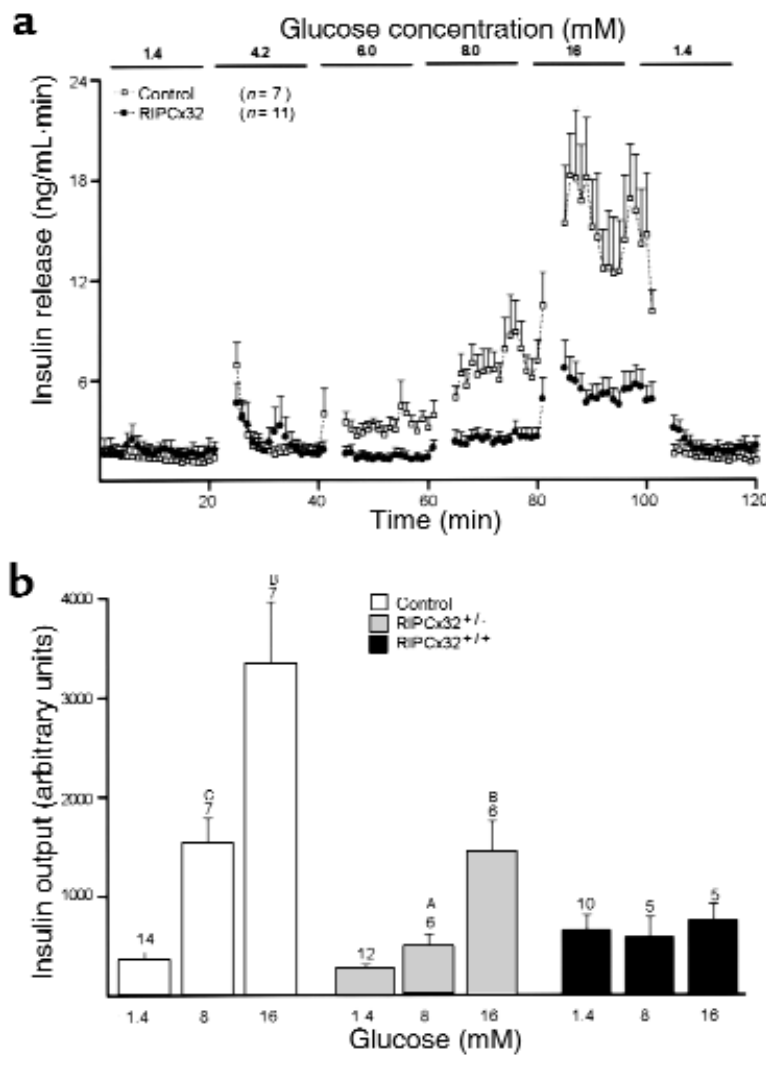

vitro studies on primary islet cells and tumoral insulinproducing cell lines, have documented a relationship between connexin-dependent cell communication and secretory function, particularly with regard to the ability of cells to increase insulin release in response to glucose $(2,4,6)$. From these studies, it was surmised that an in vivo increase in connexins would lead to enhanced insulin secretion, even though in vitro, this effect depends on the dosage of the connexin gene (6). To test whether this is also the case in vivo, we have developed transgenic animals in which a cell-specific perturbation of a connexin species resulted in a marked increase in the exchange of ions and molecules between $\beta$ cells. We show that this change is associated with a reduction of insulin secretion in response to physiologically relevant concentrations of glucose, which is sufficient to alter the glucose tolerance of the animals.

The possibility that this effect results from a nonspecific inhibition of $\beta$-cell function is unlikely, inasmuch as comparable findings were made in two independent lines of mice, with a distinct insertion site of the transgene. This view is also not supported by the findings that single transgenic $\beta$ cells were still able to increase their insulin release in response to a glucose stimulation. Our data document that when these cells were assessed within intact islets, an abnormal elevation in basal secretion of insulin and a severe reduction of the glucose-induced stimulation of this release became obvious.

From a qualitative standpoint, the secretory defects observed in isolated islets are not dissimilar from those observed in the pancreas perfusion experiments, which 
also consistently showed a poor ability of transgenic mice to increase insulin secretion when exposed to stimulatory levels of glucose. This defect was due, at least in part, to an elevated basal release, which was most obvious in homozygous mice. The quantitative differences between the two sets of experiments, e.g., with regard to the enhanced basal secretion of heterozygous mice that reached statistical significance in the islet but not the perfused pancreas experiments, are presumably attributable to differences between the two preparations which tested insulin output from different numbers of islets and under different conditions of neural and hormonal inputs $(2,25,26)$. At any rate, the finding of major secretory defects in the in situ perfused pancreas, a preparation in which most native islets are tested simultaneously in an environment that preserves their natural relationships to vessels and nerves, provides direct evidence that connexin-dependent cell-to-cell signaling contributes to $\beta$-cell modulation under the physiological conditions that prevail in vivo. They further indicate that an excess in connexins and/or in the cell-to-cell communication permitted by these proteins has the potential of significantly contributing to the loss of glucose-stimulated insulin secretion, which is consistently seen in the early pathogenesis of $\beta$-cell dysfunctions (8-10). In our model, this alteration cannot be attributed to loss of either pancreatic islets or key $\beta$-cell proteins, such as insulin, GLUT2, and glucokinase.

The finding that loss of glucose-stimulated insulin secretion took place in isolated islets but not single

\section{Figure 5}

Transgenic mice expressing Cx32 show altered tolerance to glucose. (a) After challenge with $0.11 \mathrm{mg} / \mathrm{g}$ body weight glucose, the blood levels of the sugar increased in all mice to $145-180 \mathrm{mg} / \mathrm{dL}$. In controls (solid squares), glycemia returned to basal values within 1 hour. In contrast, the glycemia of most heterozygous (open triangles) and homozygous (inverted triangles) transgenic mice did not return to the initial basal levels, which were lower $(P<0.003)$ than those of controls, during the 2 hours of the test. Data are mean \pm SEM of the indicated number of animals tested at all time points / only at time 0 . (b) The ratio of glucose-stimulated/basal glycemia averaged one in control mice (open bars) from time 60 minutes after the glucose challenge onward, but was significantly higher in both heterozygous (gray bars) and homozygous (solid bars) mice. Data are mean \pm SEM of the indicated number of animals. ${ }^{A} P<$ $0.02,{ }^{B} P<0.001$ compared with controls. cells exposed to similar in vitro conditions, which likely abolished most of the endogenous extracellular signals that modulate $\beta$ cells in situ $(2,25,26)$, provides evidence that the mechanism underlying the secretory defects of transgenic mice is likely to be dependent on cell contact. The finding that electrical synchrony, $\left[\mathrm{Ca}^{2+}\right]_{\mathrm{i}}$ increase, and dye transfer were markedly enhanced in islets of transgenic mice points to connexin-dependent coupling as a most likely mechanism, among the multiple signaling systems that $\beta$ cells use to interact directly with one another $(2,25$, 26). The mechanism whereby connexin-dependent cell-to-cell signaling exerts biologic effects is still undetermined in most systems $(1,2)$, owing to the difficulty of identifying the causal endogenous signals out of the numerous ions and molecules that permeate junctional channels $(1,2,15-17)$. In this context, our data show that the coupling enhancement observed in RIPCx32 mice was associated with elevated levels of free cytosolic calcium within intact islets, both under basal conditions and after glucose stimulation. Because these changes were not observed in single $\beta$ cells, it is likely that the enhanced $\mathrm{Ca}^{2+}$ levels resulted from the enlarged $\beta$-cell coupling (27-29). In turn, the ionic changes, possibly with the increased insulin content of pancreas and enlarged islet size, provide a plausible explanation (27-29) for the increased basal insulin output of the transgenic animals. However, in this perspective, it remains to be understood why the same ionic and islet changes resulted in a marked loss of glucose-induced insulin

a

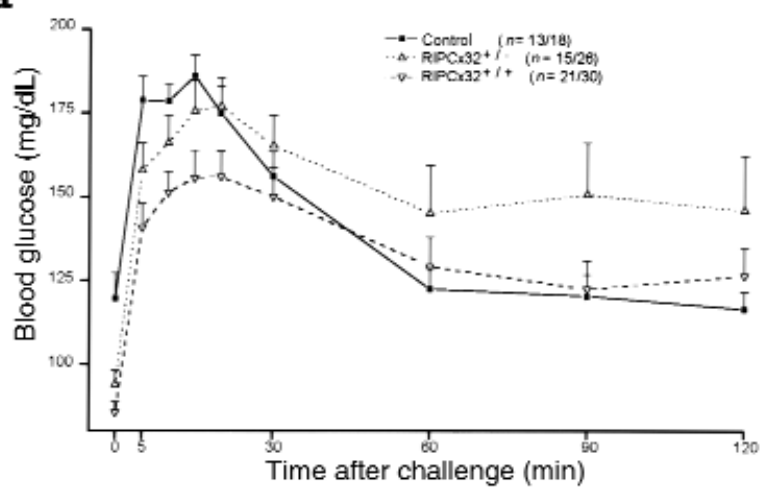

b

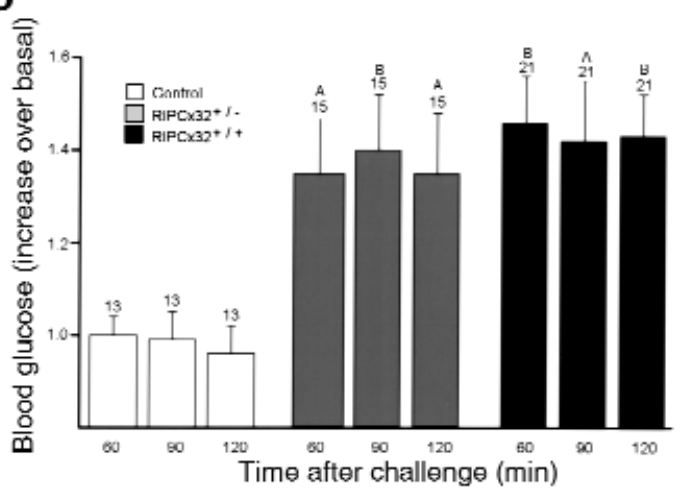


a
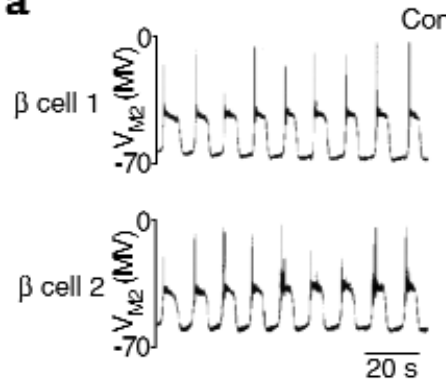

$20 \mathrm{~s}$

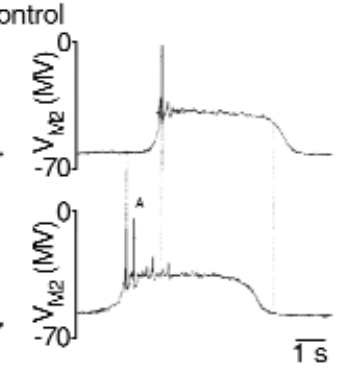

Figure 6

Transgenic mice expressing Cx32 show improved electrical synchronization and glucose-induced $\mathrm{Ca}^{2+}$ changes. (a) Left panel: typical burst activity induced by $11 \mathrm{mM}$ glucose in two control $\beta$ cells. The expanded trace of one burst shows that distant cells were slightly asynchronous in control islets. ${ }^{\mathrm{A}} 1.25$ seconds. Right panel: in islets of transgenic animals, bursts were longer and fully synchronous. (b) $\left[\mathrm{Ca}^{2+}\right]_{i}$ evaluated in the presence of $5 \mathrm{mM}$ glucose was lower in control than transgenic islets. Stimulation by $11 \mathrm{mM}$ glucose caused $\left[\mathrm{Ca}^{2+}\right]_{i}$ to increase in an oscillatory manner within most islets of both control (top panel) and transgenic mice (bottom panel). However, compared with controls, $\left[\mathrm{Ca}^{2+}\right]$ oscillations were longer and of higher amplitude within transgenic islets.

release. An excessive increase in $\mathrm{Ca}^{2+}$ during islet stimulation may contribute (30), as well as the abnormal cell-to-cell exchange of other gap junction-permeant species that are critical for insulin secretion. The intercellular communication mediated by connexin channels provides a unique mechanism for the diffusion-driven exchange of cytoplasmic ions and molecules between coupled cells, leading, at steady state, to equilibration of electrochemical gradients on the two sides of the channels $(1,2)$. Thus, secretion would be simultaneously expected from all coupled $\beta$ cells featuring a final concentration of critical signals above the threshold level required for activating the exocytosis of secretory granules. This expectation, which has received experimental support $(4,20)$, implies that insulin secretion may also become inhibited when the concentration of critical signals falls below the threshold level, e.g., as a result of the continuous dilution in an excessive cytoplasmic volume. Future studies should elucidate whether this may have taken place in RIPCx 32 mice as a result of the large increase in $\beta$-cell coupling. Furthermore, in view of the increasing evidence that different connexin species impart to junctional channels specific biophysical and regulatory features, which result in subtle differences in their conductance to current-carrying ions and permeability to molecules (15-17), it also remains to be shown whether Cx32 channels allow the exchange of ionic and molecular cocktails that would result in loss of glucose responsiveness, whatever the extent of coupling. The answer to this question awaits the availability of animal models in which coupling between $\beta$ cells is increased as a result of the expression of other connexin species. Certainly, the properties of channels made of Cx32 (15-17) differ from those made of Cx36 (31), the protein that connects native $\beta$ cells (11).
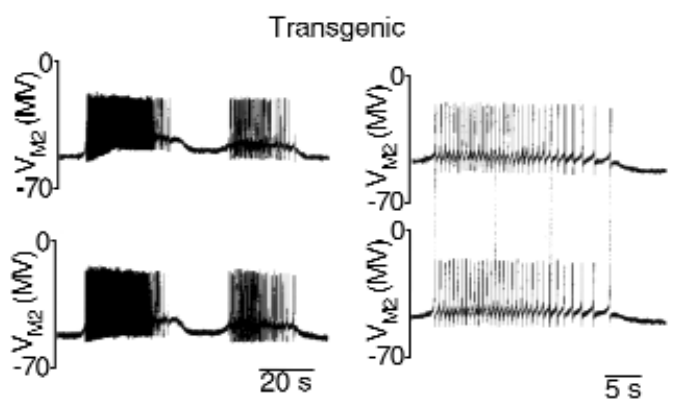

b

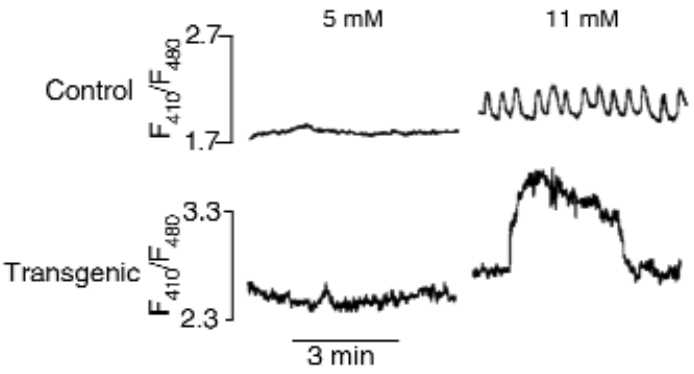

Insulin secretion is a multicellular function that obligatorily depends on proper functional integration of numerous $\beta$ cells. In situ, this integration is achieved by multiple mechanisms that involve $\beta$-cell signaling by nutrients, intrinsic and extrinsic neural inputs, and local and circulating hormones, as well as interactions between islet cells and the surrounding $\operatorname{ECM}(2,25,26)$. The present finding that direct interactions between coupled $\beta$ cells are also implicated raises the question of how the connexin-dependent signaling is integrated with the other mechanisms coordinating $\beta$ cells. Our study shows that the secretory defect resulting from a selective alteration of $\beta$ cell communication was sufficient to perturb the levels of circulating glucose, both under fasting conditions and after an acute load of the sugar, whether this was achieved by injection or food ingestion. Thus, after fasting, lowered levels of circulating glucose were measured in the transgenic mice, consistent with an increased basal secretion of insulin. Also, a sustained elevation of circulating glucose levels was observed after an acute challenge with the sugar, consistent with the limited ability of RIPCx32 mice to increase the levels of circulating insulin after stimulation. These findings indicate a significant participation of connexin-dependent cell-to-cell signaling in the multifactorial control of glycemia (8-10), in agreement with an essential contribution of this form of cell communication in the proper regulation of insulin secretion in vivo.

\section{Acknowledgments}

The authors thank L. Burkhardt, F. DeLeon, C. Devenoges, and E. Sutter for excellent technical assistance. This work was supported by grants of the Swiss National Science Foundation (31-53720.98, 32- 
49755.96), the Juvenile Diabetes Foundation International (197124), the Programme commun de recherche en génie biomédical 1999-2002 and the European Union (QLG1-CT-1999-00516).

1. Kumar, N.M., and Gilula, N.B. 1996. The gap junction communication channel. Cell. 84:381-388.

2. Meda, P. 1996. The role of gap junction membrane channels in secretion and hormonal action. J. Bioenerg. Biomembr. 28:369-377.

3. Philippe, J., Giordano, E., Gjinovci, A., and Meda, P. 1992. Cyclic adenosine monophosphate prevents the glucocorticoid-mediated inhibition of insulin gene expression in rodent islet cells. J. Clin. Invest. 90:2228-2233

4. Meda, P., et al. 1990. Rapid and reversible secretion changes during uncoupling of rat insulin-producing cells. J. Clin. Invest. 86:759-768.

5. Kohen, E., Kohen, C., and Rabinovitch, A. 1983. Cell-to-cell communication in rat pancreatic islet monolayer cultures is modulated by agents affecting islet-cell secretory activity. Diabetes. 32:95-98.

6. Vozzi, C., et al. 1995. Adequate connexin-mediated coupling is required for proper insulin production. J. Cell Biol. 131:1561-1572.

7. Withers, D.J., et al. 1998. Disruption of IRS- 2 causes type 2 diabetes in mice. Nature. 391:900-904.

8. Lauro, D., et al. 1998. Impaired glucose tolerance in mice with a targeted impairment of insulin action in muscle and adipose tissue. Nat. Genet. 20:294-298.

9. Kulkarni, R.N., et al. 1999. Tissue-specific knockout of the insulin receptor in pancreatic beta cells creates an insulin secretory defect similar to that in type 2 diabetes. Cell. 96:329-339.

10. Kahn, S.E., McKulloch, D.K., and Porte, D. 1997. Insulin secretion in the normal and diabetic human. In International textbook of diabetes mel litus. K.G.M.M. Alberti, P. Zimmet, R.A. DeFronzo, and H. Keen, editors. John Wiley and Sons Ltd. Chichester, United Kingdom. 337-353.

11. Serre-Beinier, V., et al. 2000. Cx36 preferentially connects $\beta$-cells within pancreatic islets. Diabetes. 49:727-734.

12. Reaume, A.G., et al. 1995. Cardiac malformation in neonatal mice lacking connexin43. Science. 267:1831-1834.

13. Paul, D.L. 1986. Molecular cloning of cDNA for rat liver gap junction protein. J. Cell Biol. 103:123-134.

14. Meda, P., et al. 1993. Differential expression of gap junction connexins in endocrine and exocrine glands. Endocrinology. 33:2371-2378.

15. Goldberg, G.S., Lampe, P.D., and Nicholson, B.J. 1999. Selective transfer of endogenous metabolites through gap junctions composed of different connexins. Nat. Cell Biol. 1:457-459.

16. Suchyna, T.M., et al. 1999. Different ionic selectivities for connexins 26 and 32 produce rectifying gap junction channels. Biophys. J. 77:2968-2987.

17. Bevans, C.G., Kordel, M., Rhee, S.K., and Harris, A.L. 1998. Isoform composition of connexin channels determines selectivity among second messengers and uncharged molecules. J. Biol. Chem. 273:2808-2816.

18. Hanahan, D. 1985. Heritable formation of pancreatic beta-cell tumours in transgenic mice expressing recombinant insulin/simian virus 40 oncogenes. Nature. 315:115-122.

19. Herrera, P.L., et al. 1994. Ablation of islet endocrine cells by targeted expression of hormone-promoter-driven toxigenes. Proc. Natl. Acad. Sci. USA. 91:12999-13003.

20. Bosco, D., Meda, P., Thorens, B., and Malaisse, W.J. 1995. Heterogeneous secretion of individual B cells in response to D-glucose and to nonglucidic nutrient secretagogues. Am. J. Physiol. 268:C611-C618.

21. Trimble, E.R., Bruzzone, R., Gjinovci, A., and Renold, A.E. 1985. Activity of the insulo-acinar axis in the isolated perfused rat pancreas. Endocrinology. 117:1246-1252.

22. Guinan, E.C., Smith, B.R., Favies, P.F., and Pober, J.S. 1988. Cytoplasmic transfer between endothelium and lymphocytes: quantitation by flow cytometry. Am. J. Pathol. 132:406-414.

23. Andreu, E., Soria, B., and Sanchez-Andres, J.V.J. 1997. Oscillation of gap junction electrical coupling in the mouse pancreatic islets of Langerhans. J. Physiol. (Lond.) 489:753-761.

24. Ropero, A.B., et al. 1999. Non-genomic actions of 17 beta-oestradiol in mouse pancreatic beta-cells are mediated by a cGMP-dependent protein kinase. J. Physiol. 521:397-407.

25. Berggren, P.O., et al. 1992. Mechanisms of action of entero-insular hormones, islet peptides and neural input on the insulin secretion process. In Nutrient regulation of insulin secretion. P.R. Flatt, editor. Portland Press. London, United Kingdom. 289-318.

26. Stagner, J.I. 1991. Pulsatile secretion from the endocrine pancreas. In The endocrine pancreas. E. Samols, editor. Raven Press. New York, New York, USA. 283-302.

27. Santos, R.M., et al. 1991. Widespread synchronous $\left[\mathrm{Ca}^{2+}\right]_{\mathrm{i}}$ oscillations due to bursting electrical activity in single pancreatic islets. Pflugers Arch. 418:417-422.

28. Bertuzzi, F., et al. 1999. Mechanisms of coordination of $\mathrm{Ca}^{2+}$ signals in pancreatic islet cells. Diabetes. 48:1971-1978.

29. Jonkers, F.C., Jonas, J.C., Gilon, P., and Henquin, J.C. 1999. Influence of cell number on the characteristics and synchrony of $\mathrm{Ca}^{2+}$ oscillations in clusters of mouse pancreatic islet cells. J. Physiol. 520:839-849.

30. Malaisse, W.J., et al. 1999. Possible participation of an islet B-cell calcium-sensing receptor in insulin release. Endocrine. 11:293-300.

31. Srinivas, M., et al. 1999. Functional properties of channels formed by the neuronal gap junction protein connexin36. J. Neurosci. 19:9848-9855. 